\title{
Effect of aging and pre-sintering surface treatment of zirconia cores on chipping of veneered zirconia crowns
}

\author{
Hanaa F Mahmoud $^{1 *}$, Yasser F Gomaa ${ }^{1}$, A Nour A Habib ${ }^{2}$ \\ ${ }^{1}$ Department of Biomaterials, Faculty of Dentistry, Minia University, 61519 Minia, Egypt \\ ${ }^{2}$ Department of Biomaterials, Faculty of oral and dental medicine, Cairo University, 12345 Cairo, Egypt \\ * Correspondence: hanaafarouk@yahoo.com ; Tel: +201113660363; Fax: +20 862347767
}

\section{Key words \\ Nanosilica \\ Zirconia \\ Chipping \\ Veneer}

Article information

Received: 19 October 2019

Revised: 29 October 2019

Accepted: 29 October 2019

\begin{abstract}
Aim: This study was conducted to study the effect of surface treatment of zirconia cores by nanosilica before sintering on veneers chipping and to evaluate the effect of aging in terms of thermocycling and cyclic loading on veneer chipping before and after surface treatment.

Method: Model acrylic tooth was prepared for zirconia crown, twenty silicon impressions were recorded and epoxy resin dies were produced. Twenty zirconia cores were fabricated by $\mathrm{CAD} / \mathrm{CAM}$ system and divided into 2 groups $(n=10)$ group I was the control which veneered with porcelain by hand layering technique while group II was subjected to treatment by nanosilica slurry before sintering then veneered and fired to produce crowns. The crowns were cemented by resin cement on their epoxy dies and they were subjected to 10000 thermocycles and 10000 cyclic loads. All crowns were loaded till chipping of veneer layer then the chipped surfaces were examined by SEM/EDX.

Results: There was no significant difference in chipping resistance between group I and group II.

Conclusions: Treatment of zirconia cores by nanosilica before sintering has no effect on chipping resistance of the veneer layer after subjecting to aging process (thermocycling and cyclic loading).
\end{abstract}

\section{Introduction}

Zirconium oxide ceramic was introduced as a restorative material for posterior teeth due to its superior mechanical properties which attributed to toughening mechanism that occurs through phase transformation from tetragonal to monoclinic crystalline form. However, zirconia is opaque and needs to be covered with an esthetic veneer $[1,2,3]$. Short-term clinical studies showed a high rate of veneer chipping $[4,5]$.

Chipping may be attributed to either inferior strength of the veneering porcelain or weakness in the zirconia-veneer bond or the difference in coefficient of thermal expansion between zirconia and porcelain [6].

Studies proved that nano silica had performed greatly in many branches of dentistry. Modifying zirconia surface in its pre-sintered stage is an effective technique to change the properties of zirconia based dental restorations [7, 8, 9].

Many previous studies documented that thermal and mechanical aging help in prediction of restorations durability is as they simulate oral conditions in thermal and mechanical fluctuations with less period of time and they have great effect on the chipping resistance $[10,11]$.

\section{Hypothesis:}

The treatment of zirconia core surface with nanosilica before sintering may increase the chipping resistance of the veneer layer.

\section{Methods:}

A model acrylic tooth (Typodont, Columbia) simulating mandibular first molar was imbedded vertically in a cylindrical Teflon mold with self-cured acrylic resin (Trayresin $^{\mathrm{TM}}$, Dentsply sirona, USA). The tooth was prepared to obtain a full anatomy ceramic crown preparation having the dimensions of $1.5 \mathrm{~mm}$ axial walls reduction, $2 \mathrm{~mm}$ occlusal surface reduction and $1 \mathrm{~mm}$ gingival margins reduction. High speed hand piece (NSK, Tokyo, Japan) was used with size 010,012 tapered diamond stones with flat end (Dentsply, sirona, UK) for preparation of axial and gingival walls and size 012 flame shaped stone (Dentsply, sirona, UK) for preparation of occlusal surface. The angle of convergence was $6^{\circ}-8^{\circ}$ and all line angles were rounded to prevent stress concentration.

Twenty silicon impressions (Speedex ${ }^{\circledR}$, Coltène/Whaledent AGAltstätten, Switzerland) were recorded for the prepared acrylic tooth. Impressions were poured by epoxy resin die material (Kemapoxy 150, CMB international, Egypt) and the resulted dies dimensions were measured by a digital caliper (APT, china). Dies with dimensions exceed the range of error $\pm 0.1 \mathrm{~mm}$ were discarded.

Each die was coated with a thin layer of optical reflection spray (Occlutec Spray, Renfert Dental Corp, USA) then optical impressions were recorded and twenty zirconia cores were designed and milled using computer aided design/ computer aided manufacturing (CAD/CAM) machine (Ceramill map400, 
Amnn Girrbach, Austria) with a uniform thickness of $1 \mathrm{~mm}$ and with cuspal inclination of $30^{\circ}$. Milled cores were air dried with oil free air for 1 minute.

Cores were then divided into 2 groups $(n=10)$, group I was the control in which zirconia cores were veneered without pretreatment. While group II cores were veneered after treatment by nanosilica.

For group I, zirconia cores were sintered in a sintering furnace (Ceramill therm, Amnn Girrbach, Austria) following the manufacturer instructions, this was followed by fabrication of a full contour wax pattern onto one of the copings to mimic the final veneer layer dimensions with cuspal inclination of $30^{\circ}$; silicon impression was recorded for the pattern. This silicon key provided a uniform thickness and shape of the veneer layer for all specimens. Veneering porcelain $\left(\mathrm{GC}^{\circledR}\right.$ Initial, Illinois, America) was sequentially built up by the same technician following the manufacturer's instructions with the help of the silicon key followed by firing according to manufacturer instructions. The thickness of the crowns was measured with a digital caliper to ensure uniformity among all specimens.

For group II nanosilica slurry was prepared by mixing the nanosilica powder of average size $40 \mathrm{~nm}$ (Jiangsu, Mainland, China) with ethyl alcohol (Elahram, Cairo, Egypt) by ratio $3: 1$ wt \% (this ratio was determined according to a pilot study). The slurry was applied to the outer surface of zirconia cores with porcelain brushes size 4 and 6 (Koli, Bredent, Germany) where size 4 brush was used first to cover the core with the nanosilica slurry and then size 6 brush was used to smoothen the surface and ensure that there is no areas devoid of the slurry. Surface treated zirconia cores were sintered in a sintering furnace following the manufacturer instructions and veneered after sintering as group I.

Veneered crowns were cemented to their corresponding dies using resin cement (Rely ${ }^{\mathrm{TM}} \mathrm{x}$ ultimate3M Deutschland, Germany). The cement was mixed and applied to the fitting surface of the crowns according to manufacturer instructions. The crowns were seated firmly and $1 \mathrm{~kg}$ weight was applied on the occlusal surface for 3 minutes by the use of loading device to ensure equal pressure for cementation of all specimens [2]. That was followed by light curing (LED blue phase, Ivoclar Vivadent, Germany) from each side for 10 seconds. The specimens were left undisturbed for 15 minutes and stored in distilled water for 24 hours.

The cemented crowns were placed in a thermocycling machine (Robota automated thermal cycle; Bilge, Turkey). Thermocycling was performed for 10000 cycles intermittently with a 300 cycles per day in a water bath; dwell times were 25 seconds in low temperature point of $5{ }^{\circ} \mathrm{C}$ and the high temperature point was $55^{\circ} \mathrm{C}$ with the lag time of 10 seconds.

The thermocycled crowns were stored in distilled water for 24 hours and after that they were transferred to chewing simulator (Robota, ad-tech technology, Germany) to receive 10000 successive compression loads with 200 N. All specimens were stored in distilled water for 24 hours.
Each cemented crown was fixed in the lower jaw of the universal testing machine (Instron, 3345L8741, Assembled Canton, USA). Compressive load was applied directly to the central fossa of crowns by a steel ball ( $5 \mathrm{~mm}$ in diameter) with rate of loading $0.5 \mathrm{~mm} / \mathrm{min}$. A piece of polyethylene sheet was placed between the ball and the crown in order to properly distribute the load.

The load at break was recorded and the area of loading was determined by the help of articulating paper (Zogear, China) to determine the points of loading between cusps and the steel ball. As the cuspal inclinations were tangential to the steel ball in certain points so the line between two opposing points is the diameter of the formed circle. Software design (3D CAD Solid works 2015) [12] was used to help in drawing the formed circle and calculating the area (Figure 1). By knowing the diameter of the drown circle the area (A) could be calculated through the following equation:

$$
\boldsymbol{A}=\pi r^{2}
$$

Where $\pi=3.14$ and $\mathrm{r}$ is the radius of the resulted circle.

Load was applied until chipping of the veneer layer took place. The load at chipping for each specimen was recorded and the compressive chipping stresses were calculated using the following equation:

$$
\text { Chipping stress }(\mathbf{M P a})=\frac{\text { Load at chipping }(\mathbf{N})}{\text { Stress area }\left(\mathbf{m m}^{2}\right)}
$$
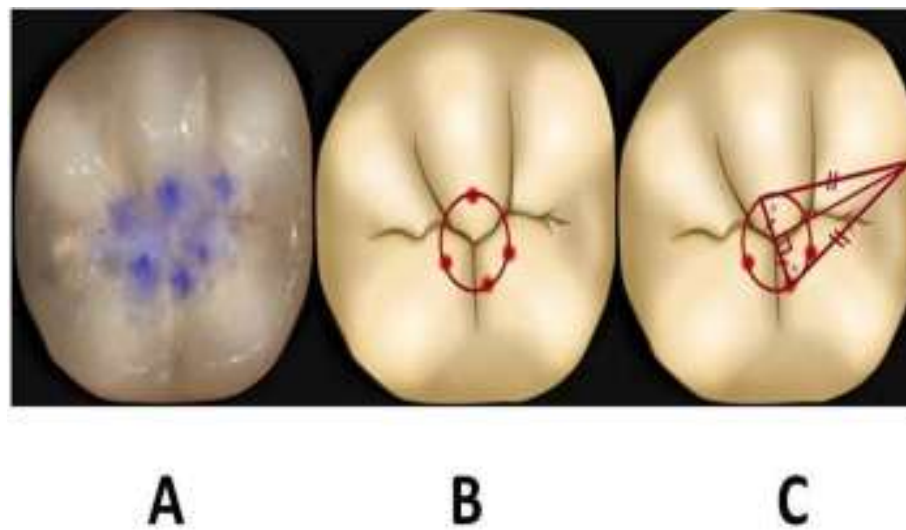

Figure 1: Carbon paper marks show loading points of steel ball on the crown (A). Diagram defines the loading points (B). Method of calculation of area of loading (C).

Chipped surfaces were coated with gold by gold sputtering machine (JEOL, JFC-1100E, Fine coat, USA.) then examined by scanning electron microscope (SEM) (JSM-IT200, JEOL ltd, Tokyo, Japan) and elemental analysis was performed by using energy dispersive $x$ ray spectroscopy $(\mathrm{EDX})$ in order to reveal the presence or absence of silica and its percentage.

\section{Statistical analysis}

Calculations and statistical analyses were performed using statistical software (SPSS 20.0, SPSS Inc., Chicago, IL, USA). 
The veneer fracture loads and the differences between groups were calculated using one-way analysis of variance (ANOVA) after tests of normality (Shapiro-Wilk, $\mathrm{P}>0.05$ ). Independent student t-test was used to compare between means. Statistically significant level was considered when calculated probability $(\mathrm{P}$ value) was less than 0.05 .

\section{Results:}

\subsection{Chipping resistance:}

There was no significant difference between both groups in chipping resistance ( $\mathrm{p}$ value > 0.05). Group I showed higher mean of chipping load which was $938.272 \pm 338.109 \mathrm{~N}$ with chipping stress of $298.812 \pm 107.678 \mathrm{MPa}$. While group II mean of chipping load was $820.913 \pm 396.200 \mathrm{~N}$ with chipping stress of $261.270 \pm 126.178 \mathrm{MPa}$.

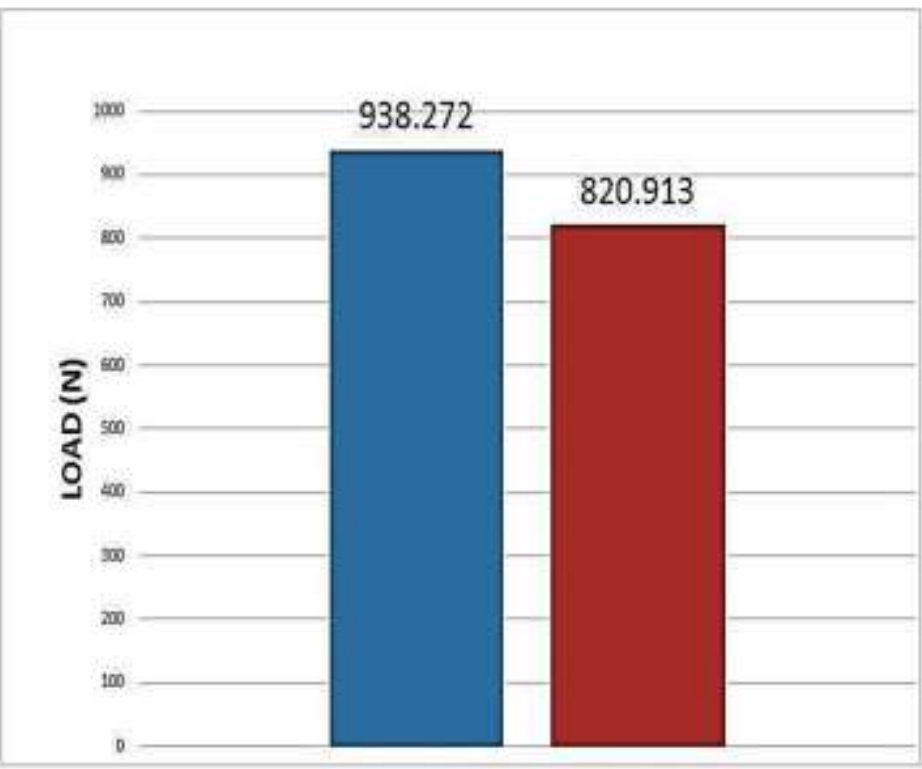

Group I Group II

Figure 2: Means of chipping load of both groups.

\subsection{SEM and EDX results:}

Scanning electron microscope examination and EDX analysis showed that the failure was mainly cohesive $(80 \%$ of specimens) in group I where chipping occurred within the porcelain veneer layer; as EDX elemental analysis of the chipped area revealed the presence of different concentrations of the components of porcelain as silicon $(\mathrm{Si})$, calcium $(\mathrm{Ca})$ aluminium ( $\mathrm{Al}) \mathrm{Na}, \mathrm{K}, \mathrm{O}$ ) with $0 \%$ zircon $(\mathrm{Zr}$ ) element which means that zirconia cores was covered with porcelain (Figure 3, 4).

The mode of failure in group II was mixed. It was predominantly adhesive with islands of aggregation of nanosilica on chipped zirconia surface and its corresponding porcelain chip indicating cohesive failure within silica layer (Figure 5, 6).

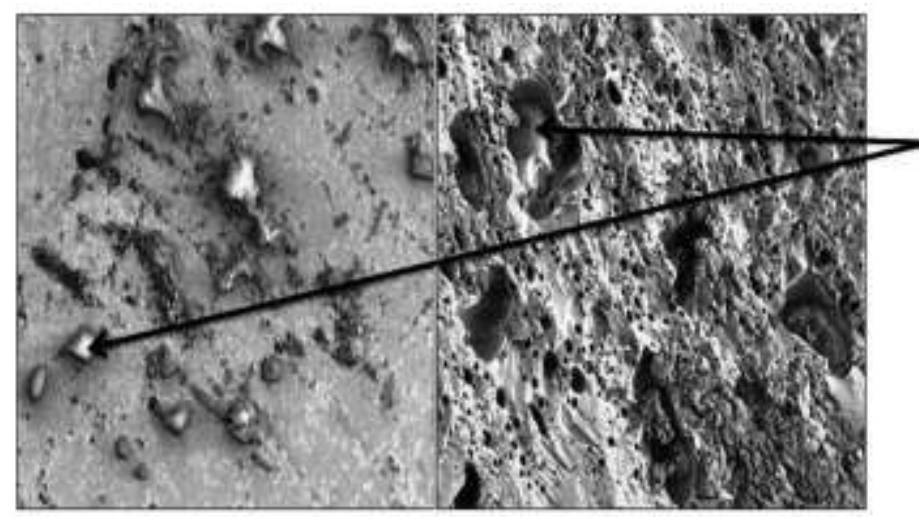

A

B

Figure 3: SEM (800X) micrographs show the surface topography of zirconia core of group I (A) and the opposing porcelain veneer surface of the same sample (B) after chipping; arrows refer to silica rich areas according to EDX analysis (cohesive mode of failure).

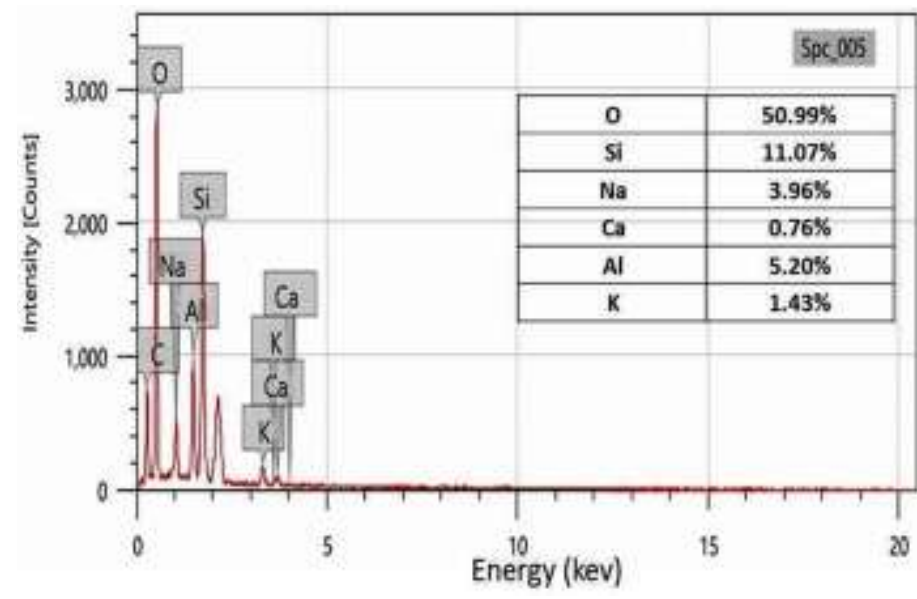

Figure 4: EDX analysis of zirconia surface of group I (cohesive mode of failure).

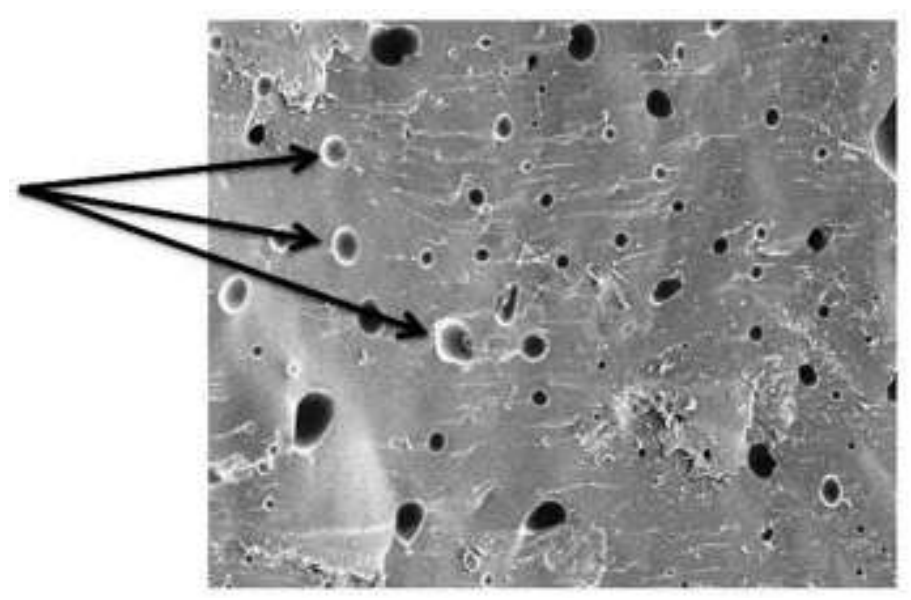

Figure 5: SEM (800X) micrograph shows the surface topography of a porcelain chip of group II; arrows referred to nanosilica aggregation. 


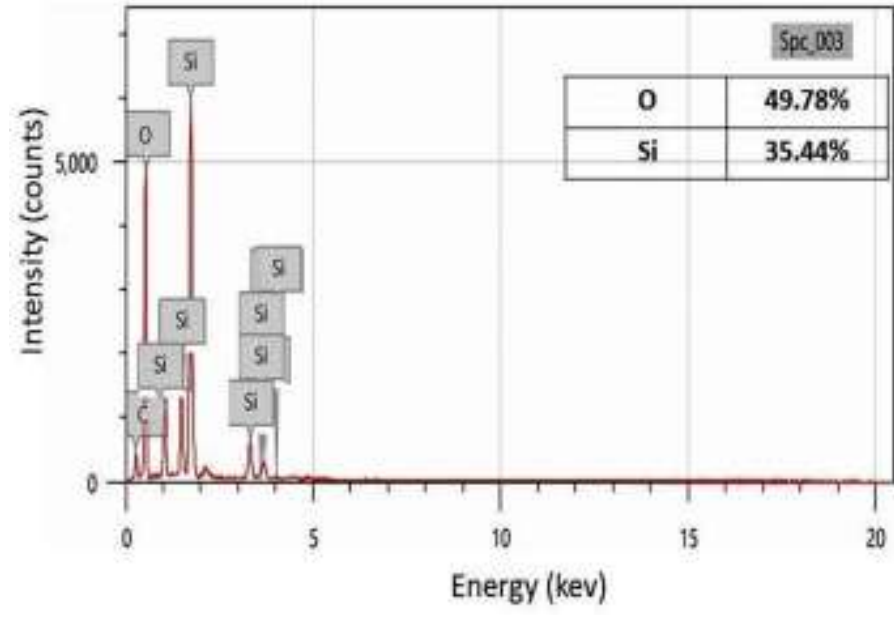

Figure 6: EDX analysis of nanosilica aggregation of group II.

\section{Discussion:}

This study was conducted to compare between the chipping resistance of nanosilica treated zirconia-porcelain interface after thermocycling and cycling loading and the nontreated ones.

Surface treatment of zirconia core before veneering is documented to be beneficial in many literatures $[13,14]$. To the knowledge of the author there is no documented literature for the advantages and disadvantages of using nanosilica for treatment of zirconisa cores prior to veneering on chipping resistance.

According to ISO 11405, the use of 500 thermal cycles between $5{ }^{\circ} \mathrm{C}$ and $55^{\circ} \mathrm{C}$ is considered to be suitable to simulate short-term aging of dental materials [10]. In addition, Gale and Darvell supposed that 10000 cycles might represent approximately 1 year of in vivo functioning, with 20 to 50 cycles considered equivalent to a single day. Combining both thermocycling and cyclic loading is more clinically relevant protocol and might give prediction of longer time service [15, $16,17]$

The chipping load of group I was comparable to the results of previous studies [18, 19]; this may support methods of fabrication of veneer and study design.

Group II showed non-significant difference in chipping resistance than group one. It is obvious that the values of chipping load of both groups were within the accepted range of ISO 6872 and 9693 for ceramic coping and veneering porcelain $[20,21]$.

Mode of failure in group I was cohesive within the veneer layer which indicated a good bonding between zirconia and veneer layer. Gautam et al 2016 [22] stated that residual stresses within the veneer are linked to the high prevalence of veneer chipping observed in clinical trials of zirconia crowns. Belli et al. 2013 [23] reported that the thermal mismatch between the zirconia infrastructure and the veneer porcelain, as well as the rate used for cooling zirconia or veneer crowns, would be directly proportional to the magnitude of residual stresses built within the veneer layers. Lohbauer et al. 2014 [24] reported the results on the fracture of a veneered zirconia from an inner thermal crack fractographic analysis and showed that the fracture may initiate from internal thermal flaws, and not exclusively from contact cracks, radial cracks or marginal defects.

As stated by many researchers that chipping mainly occurred due to difference in coefficient of thermal expansion which lead to unfavorable thermal stresses at the interface between silica and porcelain veneer layer [25-26]. However, the SEM and the EDX results indicate the strong bond between the silica coat and zirconia.

Mode of failure in group II was predominantly adhesive between porcelain layer and nanosilica layer as EDX elemental analysis showed the diffusion of nanosilica within the porcelain veneer; that was revealed by presence of silica rich aggregations on the chipped porcelain and on the zirconia cores. The failure may be attributed to difference in coefficient of thermal expansion between nanosilica and porcelain veneer as reported by Sharma et al. 2015 [27] that the nano sized particles has higher coefficient of thermal expansion than larger size particles of the same material (they reported that the increase could reach $51 \%)$.

According to The results of this study did not support the hypothesis but revealed that surface treatment of pre-sintered zirconia with nanosilica did not increase chipping resistance of veneer layer.

\section{Conclusions:}

Within the limitations of this study it was concluded that the treatment of pre-sintered zirconia cores by nanosilica has no significant effect on chipping resistance of veneer layer when the crowns were subjected to thermocyclic and cyclic loading, however the results was within the accepted range of ISO standards for ceramic coping and veneering porcelain.

\section{Recommendation:}

On the basis of this study it was recommended to:

1- Make further research on nanosilica layer thickness, particle size and shape as that may play a role in chipping resistance of veneer layer.

2- Study different types of veneering porcelain to confirm the theory of role of difference in coefficient of thermal expansion on chipping resistance.

Funding:- The authors received no specific funding for this work

\section{References}

[1] Bona A, Pecho O, Alessandretti R. Zirconia as a dental biomaterial Materials. 2015;8(8):4978-91.

[2] Alsarani M, Souza G, Rizkalla A, El-Mowafy O. Influence of crown design and material on chipping-resistance of all-ceramic molar crowns: An in vitro study. Dental and medical problems. 2018;55(1):35-42. 
[3] Benetti P, Pelogia F, Valandro LF, Bottino MA, Della Bona A. The effect of porcelain thickness and surface liner application on the fracture behavior of a ceramic system. Dental materials. 2011;27(9):.53-948

[4] Priyadarsini S, Mukherjee S, Mishra M. Nanoparticles used in dentistry: A review. Journal of oral biology and craniofacial research. 2018;8(1):58-67.

[5] Golpayegani MV, Sohrabi A, Biria M, Ansari G. Remineralization effect of topical NovaMin versus sodium fluoride $(1.1 \%)$ on caries-like lesions in permanent teeth. Journal of dentistry (Tehran, Iran). 2012;9(1):68.

[6] Skienhe H, Habchi R, Ounsi H, Ferrari M, Salameh Z. Structural and Morphological Evaluation of Presintered Zirconia following Different Surface Treatments. The journal of contemporary dental practice. 2018;19(2):156-65.

[7] Blatz MB, Bergler M, Ozer F, Holst S, Phark J-H, Chiche GJ. Bond strength of different veneering ceramics to zirconia and their susceptibility to thermocycling. American journal of dentistry. 2010;23(4):213-6.

[8] Bhowmick S, Meléndez-Martínez JJ, Zhang Y, Lawn BR. Design maps for failure of all-ceramic layer structures in concentrated cyclic loading. Acta materialia. 2007;55(7):2479-88.

[9] Shahin AMA-W, Ahed Mohammed. Masri, Radi M. Zirconia-Based Restorations: Literature Review. International Journal of Medical Research Professionals. 2017;3(2):253-60.

[10] Larsson C, Wennerberg A. The clinical success of zirconia-based crowns: a systematic review. International Journal of Prosthodontics. 2014;27(1):253-60.

[11] Sailer I, Gottner J, Känel S, Franz Hämmerle CH. Randomized controlled clinical trial of zirconia-ceramic and metal-ceramic posterior fixed dental prostheses: a 3-year follow-up. International Journal of Prosthodontics. 2009;22(6):553-60.

[12] Corporation DSS. 175 Wyman Street, Waltham, Mass. 02451 USA: $a$ Dassault Systèmes S.A. company; 2015.

[13] Standardization Of Testing of adhesion to tooth structure. 3rd ed. Geneva: International Organization for Standardization; 2015.

[14] Gale M, Darvell B. Thermal cycling procedures for laboratory testing of dental restorations. Journal of dentistry. 1999;27(2):89-99.

[15] Kelly JR. Clinically relevant approach to failure testing of all-ceramic restorations. The Journal of prosthetic dentistry. 1999;81(6):652-61.

[16] Wiskott HW, Nicholls JI, Belser UC, Wiskott H, Nicholls J, Belser U. Stress fatigue: Basic principles and prosthodontic implications. International Journal of Prosthodontics. 1995;8(2):105-16.

[17] Vigolo P, Mutinelli S .Evaluation of zirconium-oxide-based ceramic singleunit posterior fixed dental prostheses (FDPs) generated with two CAD/CAM systems compared to porcelain-fused-to-metal single-unit posterior FDPs: a 5year clinical prospective study. Journal of Prosthodontics: Implant, Esthetic and Reconstructive Dentistry. 2012;21(4):265-9.

[18] Sorrentino R, De Simone G, Tetè S, Russo S, Zarone F. Five-year prospective clinical study of posterior three-unit zirconia-based fixed dental prostheses. Clinical oral investigations. 2012;16(3):977-85.

[19] Örtorp A, Kihl ML, Carlsson GE. A 5-year retrospective study of survival of zirconia single crowns fitted in a private clinical setting. Journal of Dentistry. 2012;40(6):527-30.

[20] ISO 6872 Dentistry - Ceramic materials. Geneva, Switzerland: International Organization for Standardization; 2008

[21] ISO 9693 Dentistry - Metal-ceramic dental restorative systems. Geneva, Switzerland: International Organization for Standardization; 1999

[22] Gautam C, Joyner J, RaoJ, Gautam A, Vajtaia R. Zirconia based dental ceramics: structure, mechanical properties, biocompatibility and applications. Dalton transactions. 2016;48.

[23] Belli R, Frankenberger R, Appelt A. Dent. Mater. 2013;29:181-90.

[24] Lohbauer U, Belli R, Arnetzl G, Scherrer S, Quinn G, Case Stud. Eng. Failure Anal. 2014;2:100-6.

[25] Gibbs CH, Anusavice KJ, Young HM, Jones JS ‘Esquivel-Upshaw JF. Maximum clenching force of patients with moderate loss of posterior tooth support: a pilot study. The Journal of prosthetic dentistry. 2002;88(5):498-502. [26] Ferrario VF, Sforza C, Zanotti G, Tartaglia GM. Maximal bite forces in healthy young adults as predicted by surface electromyography. Journal of dentistry. 2004;32(6):451-7.

[27] Sharma C, Bhatt S, Kumar R, Kumar M. Size,shape and temperature effect on nanomaterials.Indian journal of pure and applied physics.2015;53:768-75. 